\title{
ESTUDO DAS PROPRIEDADES LINGUÍSTICAS E DISCURSIVAS DO GÊNERO RESENHA ACADÊMICA
}

\author{
STUDY OF LINGUISTIC AND DISCURSIVE \\ PROPERTIES OF THE ACADEMIC REVIEW
}

GENRE

Gustavo Ximenes Cunha ${ }^{1}$

\section{RESUMO}

Neste artigo, realizamos um estudo do gênero resenha acadêmica. Três razões justificam o estudo desse gênero. Em primeiro lugar, a resenha é um gênero acadêmico em que a argumentação é central. Em segundo, ela constitui um importante instrumento de circulação e consolidação do saber nas diferentes áreas do conhecimento. Em terceiro lugar, esse gênero de textos é um dos mais solicitados pelos professores nos diferentes estágios de um curso superior. Com base na perspectiva descendente de estudos das práticas sociais, proposta por Bakhtin/Volochínov, o estudo que apresentamos não limita a compreensão do gênero a seus aspectos formais de composição. Sem desconsiderar esses aspectos, o estudo se inicia pela abordagem da dimensão contextual da resenha. Em seguida, focaliza a macroestrutura do gênero. Por fim, estuda a sua dimensão linguística.

Palavras-chave: Resenha acadêmica. Argumentação. Gêneros textuais. 


\section{INTRODUÇÃO}

Ao longo de um curso superior, o estudante atua em diferentes práticas, tais como assistir a aulas, participar de seminários, elaborar trabalhos de conclusão de disciplina, redigir relatórios de pesquisa, produzir artigos científicos e monografias, resumir e resenhar obras acadêmicas, participar de reuniões de grupos de pesquisa, etc.

Em todas essas práticas, é fundamental que o estudante seja capaz de produzir e interpretar textos argumentativos escritos ou falados. Afinal, uma das habilidades exigidas de um futuro profissional, em qualquer campo de trabalho, é que ele seja capaz de apresentar um ponto de vista e de defendê-lo por meio de argumentos que demonstrem a sua capacidade de se posicionar criticamente diante de algum aspecto da realidade. Outra habilidade exigida desse futuro profissional é que ele seja capaz de compreender o ponto de vista do outro, avaliando a pertinência da opinião em questão e julgando a consistência dos argumentos apresentados. E esse outro pode ser um colega integrante de grupo de estudos, um professor que busca convencer os alunos da relevância de determinado tópico ou o autor de dado artigo ou livro.

$\mathrm{Na}$ academia, alguns textos são mais argumentativos que outros. A resenha, por exemplo, é um dos gêneros de textos mais argumentativos desse ambiente. Inclusive, é essa dimensão fortemente argumentativa da resenha que a diferencia do resumo. Enquanto na resenha o autor deve expor opinião sobre uma dada obra, no resumo, a princípio, 
o autor deve apresentar apenas, em linhas gerais, o conteúdo veiculado.

Neste artigo, vamos nos deter ao estudo da resenha acadêmica, e isso por três razões. A primeira é que, como foi dito, a resenha é um gênero acadêmico em que a argumentação é central. A segunda razão é que a resenha constitui um importante instrumento de circulação e consolidação do saber nas diferentes áreas do conhecimento. Por meio dela, os especialistas tomam conhecimento de novas obras, bem como dos critérios convencionados em sua área, para julgar se o trabalho é relevante ou não (MOTTA-ROTH, 2001). A terceira razão é que esse gênero de textos é um dos mais solicitados pelos professores nos diferentes estágios de um curso superior. Do primeiro ao último período de uma graduação, somos sempre solicitados a produzir resenhas de diferentes obras (livros, artigos, capítulos de livros), tendo em vista a necessidade de o estudante desenvolver a capacidade de se posicionar criticamente diante de determinado assunto, refletindo sobre esse tema e sobre a maneira como ele foi abordado pelo autor (MATENCIO, 2003).

Para realizar o estudo da resenha, vamos abordar três aspectos desse gênero. Com base na perspectiva descendente de estudos das práticas sociais proposta por Bakhtin/Volochínov (2012[1929]), o estudo se inicia pela abordagem da dimensão contextual da resenha ou pela abordagem de seu contexto de produção e recepção. Em seguida, focaliza a macroestrutura do gênero e, por fim, focaliza a dimensão linguística. 


\section{CONTEXTO DE PRODUÇÃO E RECEPÇÃO}

A resenha acadêmica é um gênero de textos cuja finalidade principal é apresentar juízos sobre uma obra recentemente publicada ou traduzida, convencendo o leitor a ler ou não, a adquirir ou não essa obra. Configura-se como um texto não muito longo, que descreve e avalia (elogia ou critica) determinado trabalho. A resenha funciona, assim, como guia de leitura e aquisição de publicações (MOTTA-ROTH; HENDGES, 2010).

Todos os anos, as editoras de obras acadêmicas, seja no Brasil seja no exterior, lançam uma quantidade enorme de novos títulos no mercado, os quais pertencem às mais diversas áreas do conhecimento. Essa quantidade de novos títulos dificulta que um pesquisador, por mais empenhado que seja, possa estar a par de tudo o que vem sendo publicado na sua área de interesse. Por um lado, há escassez de tempo para ler tudo. Por outro, há escassez de recursos financeiros para adquirir todos os livros, já que os livros, ainda mais os acadêmicos, custam caro. Há também o fato de que nem tudo o que se publica será de interesse para o ambiente acadêmico. Tendo em vista essas restrições, a resenha funciona como um instrumento muito pertinente para nos ajudar a selecionar o que ler, a escolher a obra que merece esse dispêndio de tempo e dinheiro.

Nesse sentido, a resenha é um gênero fortemente argumentativo ou persuasivo, já que avalia e julga a contribuição que a obra resenhada traz para a área, as características da composição e a capacidade do autor (CARVALHO, 2005). Por esse motivo, quem escreve uma resenha, o resenhista, deve ser um especialista em determinada área do conhecimento. 
Afinal, o papel de um resenhista é semelhante ao de um juiz, porque ele tem a função de julgar os méritos e as falhas de dada obra, a fim de auxiliar o leitor. E, para que isso aconteça, é preciso que o resenhista tenha conhecimentos aprofundados da área em que o livro se insere.

Assim, quem escreve uma resenha deve ter em mente o papel que assume de convencer o outro a respeito de determinada tese sobre uma obra. Ou seja, ao final da leitura de uma resenha, o leitor deve ter clareza da opinião do resenhista sobre a obra resenhada. Quem escreve uma resenha sobre um livro, por exemplo, deve se preocupar em formular de maneira evidente a opinião sobre esse livro. Para o resenhista, esse livro é fundamental para a área dos conhecimentos em que se insere? Ou, para ele, esse livro não acrescenta nada de substantivo ao que já se sabe sobre o tema? O leitor de uma resenha, ao final da leitura, deve ser capaz de responder a essas perguntas.

Além disso, quem escreve uma resenha deve ter a consciência de que precisa trazer argumentos consistentes para defender sua tese ou opinião sobre a obra. Se uma resenha trouxer a tese sobre uma obra, mas não trouxer argumentos que a sustentem, o leitor terá todo o direito de se perguntar: "Por que o resenhista pensa assim? Será que ele está certo em pensar assim?". Se um resenhista disser "Esse livro é fundamental para a área dos conhecimentos em que se insere", mas não deixar claro por que pensa dessa forma, o leitor poderá questionar a validade da tese. E todo resenhista deve evitar a possibilidade de questionamentos sobre a tese que apresenta. Afinal, se eu, como leitor de uma resenha, questiono a tese 
do resenhista, duvidando que ela seja válida, eu questiono implicitamente a capacidade do resenhista de avaliar de modo crítico e pertinente uma obra. E dúvidas sobre a capacidade de um resenhista podem derrubar a sua reputação de especialista em determinada área de conhecimento, o que é bastante problemático (MOTTA-ROTH, 2001).

Por isso, toda tese sobre um livro deve ser acompanhada de argumentos que a sustentem. E vale chamar a atenção para o fato de que os argumentos devem ser consistentes, o que significa que, por estarmos tratando da resenha acadêmica, os argumentos devem ser baseados em valores caros ou importantes para a área do livro. Então, suponhamos que, em uma resenha, a tese sobre uma obra seja esta: "Esse livro não acrescenta nada de substantivo ao que já se sabe sobre o tema". Para sustentar essa tese, qual argumento podemos considerar como sendo o mais consistente?

Argumento 1: A capa do livro é muito pouco colorida e não apresenta desenhos interessantes e atrativos.

Argumento 2: Nos últimos anos, foram publicados muitos livros que tratam do mesmo assunto e voltados para o mesmo público.

Para julgar a adequação ou a inadequação de cada um desses argumentos, temos que pensar que o público de uma resenha é formado por estudiosos ou especialistas na área e que a resenha vai circular no ambiente acadêmico. Para esse público e para o ambiente em que o texto vai circular, as características da capa não interferem em nada na qualidade do livro. Mas, nesse contexto, o fato de um livro trazer informações que 
outros livros recentemente publicados já trazem interfere, sim, na qualidade do livro ou, pelo menos, faz com que ele seja visto como menos relevante que um livro que trata de assunto inédito. Portanto, para defender que "Esse livro não acrescenta nada de substantivo ao que já se sabe sobre o tema", o autor de uma resenha acadêmica poderá usar o argumento 2 e não poderá usar o argumento 1 .

Esse exemplo mostra que o que vai dizer se um argumento é ou não consistente é a situação de produção da resenha. Para quem estou escrevendo? Onde esse texto vai circular? Para que serve esse texto? Assim, em uma resenha sobre um livro infantil e publicada numa revista voltada para crianças, é possível que o argumento 1 seja considerado consistente para defender que um dado livro não é bom. Afinal, para esse público, as características da capa de uma obra têm papel altamente relevante, por ajudarem a despertar o interesse das crianças pela leitura.

Além de defender sua tese com argumentos consistentes, quem escreve uma resenha deve ter em mente que o leitor precisa chegar a uma conclusão clara sobre o livro. Isso porque, ao lermos uma resenha, queremos saber se o resenhista aconselha ou não a leitura do livro. E essa conclusão (ler ou não ler?) precisa ser deduzida ou derivada dos argumentos. Vejamos dois exemplos.

$\mathrm{Na}$ primeira situação, o resenhista apresenta uma tese favorável a um livro e expõe um argumento que justifica essa tese. Logo, a conclusão precisa aconselhar o leitor a adquirir a obra. 
Tese: Esse livro é fundamental para a área dos conhecimentos em que se insere.

Argumento: (Porque) Ele aborda teorias que ainda não foram suficientemente aplicadas e discutidas entre nós.

Conclusão: (Portanto) O livro é indicado para quem procura conhecer novas teorias.

Na segunda situação, o resenhista ressalta um problema de um livro e traz um argumento que justifica sua opinião. Logo, a conclusão deve ser compatível com essa postura, e o resenhista pode até aconselhar a leitura, mas fazendo restrições.

Tese: Esse livro não acrescenta nada de substantivo ao que já se sabe sobre o tema.

Argumento: (Porque) Muitos livros publicados nos últimos anos tratam do mesmo assunto.

Conclusão: (Portanto) O livro é superficial, e sua leitura é indicada apenas para quem é totalmente leigo ou iniciante no tema.

Neste item, vimos que, para que um texto seja uma resenha, é fundamental que seu produtor assuma o papel de especialista em determinada área dos conhecimentos, apresente de forma clara a opinião sobre a obra, defenda essa opinião com base em argumentos que possam ser considerados consistentes e relevantes pelo interlocutor visado (outro especialista) e, finalmente, extraia desses argumentos uma conclusão sobre 
a obra. É esse percurso argumentativo que o leitor espera encontrar em uma resenha, tendo em vista sua busca por saber se deve ou não adquirir uma obra.

Mas a pessoa que vai escrever uma resenha acadêmica deve saber também que esse gênero tem uma estrutura global (ou macroestrutura) característica, que corresponde às ações que um resenhista costuma realizar ao escrever. Vejamos como isso acontece.

\section{MACROESTRUTURA TEXTUAL}

Ao escrever uma resenha sobre um livro, um resenhista costuma realizar basicamente quatro ações: (1) apresentar o livro; (2) caracterizar o livro; (3) avaliar aspectos do livro; (4) recomendar (ou não) o livro (MOTTA-ROTH e HENDGES, 2010; CARVALHO, 2005).

No começo da resenha, o resenhista costuma apresentar o livro, dando uma visão geral da obra, como ocorre neste trecho:

(1) A sociologia econômica é um campo em desenvolvimento. [...] Inserida nesse campo de estudos, Redes e sociologia econômica é obra organizada pela professora Ana Cristina Braga Martes.

(RODRIGUES A. L. As pessoas e a economia: algumas possibilidades deste encontro. Rev. adm. empres. v. 50, n. 3, 2010, p. 345-346.) 
Em seguida, ele caracteriza o livro, apresentando e descrevendo, de modo bem geral, o tópico de cada capítulo ou das partes do livro.

(2) A obra está estruturada em três grandes partes que se desdobram, evidenciando a sucessão de teorias, críticas e proposições em gestão estratégica de pessoas. A primeira aborda a gestão estratégica de pessoas como alinhamento sistêmico. A segunda, como potencial competitivo. A terceira, em seus temas contemporâneos.

(ALBUQUERQUE, L. G.; LEITE, N. P.; SILVA, L. M. T. Estimulando o debate sobre a gestão estratégica de pessoas. Rev. adm. empres., v. 49, n. 4, 2009, p. 482483.)

Na sequência, o resenhista avalia aspectos do livro, tratando de modo mais detido do conteúdo de cada capítulo, julgando e discutindo pontos específicos. Nessa avaliação, podem ser apontados os méritos do livro:

(3) Outra característica marcante da obra é a postura crítica assumida ao longo de todo o texto. A leitura não se restringe à passividade, mas desperta, a todo momento, a reflexão em função dos pontos e contrapontos apresentados continuamente pelo autor.

(ALBUQUERQUE, L. G.; LEITE, N. P.; SILVA, L. M. T. Estimulando o debate sobre a gestão estratégica de pessoas. Rev. adm. empres., v. 49, n. 4, 2009, p. 482483.)

Ou, nessa avaliação, o resenhista pode chamar a atenção do leitor, alertando-o para o que considera um problema: 
(4) A obra poderia conter, também, um capítulo de conclusão, conferindo mais espaço a esclarecimentos, discussões e interrelações entre capítulos. Indo além, dada a natureza complexa do tema, seria interessante que os capítulos teóricos da primeira parte viessem todos acompanhados de textos associados, com comentários de autores convidados.

(RODRIGUES A. L. As pessoas e a economia: algumas possibilidades deste encontro. Rev. adm. empres. v. 50, n. 3, 2010, p. 345-346.)

Por fim, o resenhista recomenda ou não o livro.

(5) Neste sentido, para todos aqueles que desejam pensar o Brasil num cenário de desenvolvimento e não apenas pela ótica das políticas econômicas de curto prazo, recomenda-se a leitura dos ensaios elaborados em honra do Professor Werner Baer, que mesclam, com competência técnica, as dimensões múltiplas do processo de desenvolvimento da America Latina.

(HADDAD, P. Economic Development in Latin America, Essay in Honor of Werner Baer. Rev. Econ. Polít., v. 31, n. 1, 2011, p. 181-182.)

Nessa parte final, a recomendação pode ser acompanhada de alguma crítica.

(6) Desse modo, o livro traz grandes contribuições para a formação de pesquisadores na área, com novas ideias e perspectivas para perenizar o debate. Por outro lado, o conteúdo do livro não se mostra de fácil aplicação no meio organizacional, seja pela forma acadêmica de redação, seja pela própria complexidade do assunto. 
(ALBUQUERQUE, L. G.; LEITE, N. P.; SILVA, L. M. T. Estimulando o debate sobre a gestão estratégica de pessoas. Rev. adm. empres., v. 49, n. 4, 2009, p. 482483.)

Nesse trecho, após mencionar as "grandes contribuições" que o livro traz, o resenhista introduz uma crítica, ao dizer que "o conteúdo do livro não se mostra de fácil aplicação no meio organizacional", tendo em vista a complexidade do tema e a linguagem acadêmica. Essa mudança de perspectiva é sinalizada, no trecho, pela expressão conectiva por outro lado.

Essas quatro ações e a ordem em que elas costumam ser realizadas podem ser representadas por meio da Figura 1.

Figura 1 - Macroestrutura da resenha acadêmica

Apresentação $\rightarrow$ Caracterização $\rightarrow$ Avaliação de aspectos $\rightarrow$ (Não) Recomendação

Essas ações correspondem às diferentes partes da macroestrutura do gênero resenha. Essas partes costumam aparecer nessa ordem e podem variar em extensão, o que vai depender do que o resenhista deseja enfatizar sobre o livro. Mas é importante notar que essa macroestrutura não deve ser entendida como uma forma textual que todo resenhista deve seguir, quando da escrita de uma resenha. Na verdade, ela representa ações que costumam ser realizadas na produção da maior parte das resenhas. Porém, tendo em vista os interesses e os objetivos comunicativos de um resenhista, algumas delas podem não ser realizadas ou a ordem de realização pode ser alterada (MOTTA-ROTH; HENDGES, 2010). 
Como visto até aqui, a produção de uma resenha acadêmica envolve a busca por convencer o leitor a ler ou não uma obra recentemente publicada. Para isso, o resenhista realiza diferentes ações, como apresentar a obra e avaliá-la. De posse dessas informações, ele tem condições de produzir uma resenha que possa funcionar, isto é, que, de fato, sirva como um guia para o leitor decidir se pretende ou não adquirir uma nova publicação.

Mas uma questão ainda permanece. No dia a dia, lemos diferentes textos, e alguns nos parecem mais interessantes que outros. Diferentes jornais, por exemplo, publicam notícias sobre o mesmo fato, mas uma notícia nos parece mais interessante que outra. Sentimos que um jornalista parece estar mais certo ou parece merecer mais a nossa credibilidade que outro. $\mathrm{O}$ mesmo acontece com os artigos de opinião. Dois articulistas defendem opiniões contrárias, mas igualmente aceitáveis sobre um mesmo tema. Porém, julgamos que os argumentos de um são mais convincentes que os do outro. A maneira como um deles coloca a opinião e expressa os argumentos parece ser mais forte, mais apaixonada, mais verdadeira. Por que isso acontece, se ambos apresentam opiniões e argumentos plausíveis ou convincentes?

A diferença entre os autores está, muitas vezes, na linguagem usada, está na maneira como eles escolheram as palavras e construíram as frases de seus textos. Isso aponta para o fato de que a língua dispõe de mecanismos que nos permitem tornar nossos textos mais interessantes, convincentes, combativos, enfim, mais argumentativos. Vejamos, então, como a língua 
pode tornar a argumentação mais eficaz na escrita da resenha acadêmica.

\section{CARACTERÍSTICAS LINGUÍSTICO-DISCURSIVAS}

A língua dispõe de vários recursos que permitem tornar a resenha mais argumentativa. Esses recursos contribuem para deixar mais claro para o leitor qual é o posicionamento do resenhista acerca do livro resenhado. Aqui vamos abordar apenas alguns desses recursos. Vamos mostrar de que modo os adjetivos, os advérbios, os conectores e os substantivos podem nos ajudar a convencer o leitor do nosso ponto de vista sobre a obra resenhada.

\section{Adjetivos}

Sempre estudamos os adjetivos como sendo aquele conjunto de palavras que expressam qualidades ou atributos dos seres. Esse é um conhecimento encontrado em qualquer gramática. Assim, na frase $O$ livro amarelo, sabemos que a palavra amarelo expressa uma qualidade do livro.

Mas saber isso é saber muito pouco sobre o funcionamento dos adjetivos, sobre o modo como, realmente, os usamos para produzir textos escritos e orais. Afinal, para que servem essas palavras? Em que contexto são mais usadas? De que forma elas nos ajudam a fazer nosso ouvinte ou leitor considerar um determinado ser ou objeto de uma maneira e não de outra? Em que medida dizer que o livro é fascinante contribui mais 
para a minha argumentação que dizer apenas que o livro é amarelo?

Essas questões mostram que raramente os adjetivos são estudados como instrumentos eficazes e poderosos para argumentar. Ou seja, não pensamos no papel fundamental que eles podem exercer na construção de uma argumentação.

Nas resenhas, os adjetivos podem auxiliar o resenhista a deixar mais evidente o seu posicionamento com relação ao livro. Neste trecho, os adjetivos em itálico não deixam dúvida quanto à posição favorável do resenhista sobre o livro.

(7) $O$ trabalho de Miyazaki, baseado em cuidadosa pesquisa de dados e fatos, apresenta uma interessante e inédita metodologia de análise.

(LACERDA, A. C. As origens do investimento japonês na Ásia: um estudo do período da pré-Segunda Guerra Mundial. Revista de Economia Política, v. 30, n. 1 (117), 2010, p. 178-182.)

Ao dizer que o livro se baseia em pesquisa cuidadosa, o resenhista revela que, para ele, a pesquisa é confiável e busca convencer o leitor de que o livro pode ser adquirido sem receio. Da mesma forma, o resenhista diz que a metodologia de análise empregada no estudo é interessante e inédita, com o fim de fazer o leitor perceber ou acreditar que vale a pena ler o livro, que essa obra traz uma metodologia que, por ser interessante e inédita, deve ser conhecida pelo leitor/ pesquisador. Com esses adjetivos, o resenhista lida com valores importantes do meio acadêmico, como originalidade, cientificidade e seriedade. Para verificar a importância desses adjetivos, vejamos como o mesmo trecho fica sem eles. 
(8) O trabalho de Miyazaki, baseado em pesquisa de dados e fatos, apresenta metodologia de análise.

Sem os adjetivos, toda a carga argumentativa do trecho desaparece. Sem eles, não sabemos qual a opinião do resenhista sobre o livro e não nos sentimos mais motivados a lê-lo.

\section{Advérbios}

Os advérbios são um conjunto de palavras com sentidos muito variados. Alguns expressam a ideia de lugar (aqui, acima, dentro). Outros expressam a ideia de tempo (ontem, hoje, amanhã). Outros trazem ainda a ideia de intensidade (muito, pouco, bastante). E as gramáticas, de modo geral, definem essas palavras como sendo aquelas que modificam outras palavras, como verbos e adjetivos. Embora definições como essa possam ter valor, elas em nada ajudam as pessoas a usar os advérbios de maneira eficaz na hora de construir um texto. Saber que existem advérbios de lugar, de tempo e de intensidade e que eles modificam outras palavras não faz um resenhista saber usá-los de modo adequado para convencer o leitor a ler ou não uma obra. Assim, para convencer o leitor, qual destes argumentos seria mais convincente?

1 - O livro contribui pouco para o avanço dos estudos linguísticos.

2 - O livro contribui um pouco para o avanço dos estudos linguísticos. 
3 - O livro contribui para o avanço dos estudos linguísticos.

4 - O livro contribui muito para o avanço dos estudos linguísticos.

5 - O livro contribui demais para o avanço dos estudos linguísticos.

As cinco frases são muito parecidas. O que muda são os advérbios. Mas chama a atenção como a mudança de somente uma palavra transforma completamente o sentido de cada frase. Com a mudança dos advérbios, temos cinco argumentos completamente diferentes.

Para convencer o leitor a ler uma obra, um resenhista não escolheria os argumentos 1 e 2. Embora o argumento 2 diga que o livro contribui um pouco para o avanço dos estudos linguísticos, ele ainda é fraco para convencer alguém a ler um livro. $\mathrm{O}$ argumento 3 não traz advérbio e poderia ajudar o resenhista a alcançar seu objetivo. Mas, embora esse argumento seja mais forte que o 2, ele ainda é fraco. Para mostrar que o livro deve mesmo ser lido, o argumento 4 é melhor que o 3 , já que contribuir muito é mais forte do que apenas contribuir. Mas, se o resenhista estiver mesmo convicto da relevância da obra, o argumento 5 é imbativel. Dizer que o livro contribui demais para o avanço dos estudos linguísticos é não deixar dúvidas sobre a necessidade da leitura desse livro. Como vemos, entre os argumentos de 1 a 5, há uma gradação em termos de força argumentativa, o que é possibilitado pela simples troca ou eliminação dos advérbios (CABRAL, 2010). 
Neste trecho de uma resenha, os advérbios exercem exatamente esse papel, de tornar o texto mais argumentativo, ajudando o resenhista a fazer o leitor entender que o livro precisa ser lido.

(9) O Professor José Carlos Marion, com o livro "Contabilidade da pecuária", efetivamente vem preencher uma lacuna muito sentida em nossa bibliografia contábil.

(IUDÍCIBUS, S. Contabilidade da pecuária. Revista de Administração. v. 18, n. 3, 1983, p. 102. Disponível em: www.rausp.usp. br/download.asp?file $=\mathrm{v} 20 \mathrm{n} 01 \mathrm{p} 087$. pdf. Acesso em: 23/02/2014.)

Se retirarmos os advérbios, o argumento perde sua força original.

(10) O Professor José Carlos Marion, com o livro "Contabilidade da pecuária", vem preencher uma lacuna sentida em nossa bibliografia contábil.

\section{Conectores}

Os conectores são um conjunto de palavras e de expressões linguísticas que ajudam o produtor do texto a indicar as relações de sentido entre as informações de frases ou mesmo de porções maiores do texto, como parágrafos e capítulos. Em outros termos, os conectores desempenham a função de promover a ligação ou a "amarração" de diferentes porções ou partes do texto (ANTUNES, 2005). Assim, um conector como o mas indica que, entre duas informações, existe uma relação de oposição. Da mesma forma, uma expressão como ou seja indica que duas informações se ligam por uma relação de 
reformulação. Já o conector portanto traz uma conclusão para o que vinha sendo dito.

Do ponto de vista argumentativo, a importância dos conectores está em deixar evidentes as manobras que realizamos para convencer o outro sobre determinada opinião. Para convencer o interlocutor, o locutor pode construir textos complexos. Neles, pode introduzir argumentos para defender seu ponto de vista, rejeitar uma ideia com a apresentação de contra-argumentos, comentar partes do texto, reformular pensamentos, tornando-os mais claros para o outro, etc. E os conectores podem ser usados para evidenciar essas diferentes ações ou manobras, levando o outro (leitor/ouvinte) a aceitar a ideia que o locutor considera a mais adequada (ROULET, 2006; CUNHA, 2010, 2012).

Dessa forma, na produção de uma resenha, os conectores podem ajudar o resenhista a deixar evidentes para os leitores diferentes tipos de relações semânticas ou de sentido entre as informações. Ele pode indicar a introdução de um contraargumento desfavorável ao livro:

(11) Para manter a coerência do enfoque, os conceitos teóricos utilizados derivam de Fayol e dos neoclássicos. Mas Marion não deu a devida atenção a temas que seriam essenciais para elucidar melhor os percalços da economia.

(IUDÍCIBUS, S. Contabilidade da pecuária. Revista de Administração.v. 18, n. 3, 1983, p. 102. Disponível em: www.rausp.usp.br/download.asp?file=v20n01p087. pdf. Acesso em: 23/02/2014.) 
Ou o resenhista pode sinalizar a introdução de um contraargumento favorável:

(12) A abrangência dos temas acaba sendo um fator limitativo para o desenvolvimento dos métodos apresentados. Em contrapartida, oferece a oportunidade para que o leitor tenha um primeiro conhecimento dos temas abordados pela Estatística.

(FARIA, J. H. Organização do trabalho. Revista de Administração. v. 20, n. 1, 1985, p. 90. Disponível em: www.rausp.usp.br/download.asp?file=v20n01p087. pdf. Acesso em: 23/02/2014.)

Com os conectores, o resenhista pode também sinalizar a introdução de um argumento favorável ao livro:

(13) O trabalho de Miyazaki, baseado em cuidadosa pesquisa de dados e fatos, apresenta uma interessante e inédita metodologia de análise. Isso porque leva em conta os aspectos institucionais, históricos, geopolíticos e geoeconômicos.

(LACERDA, A. C. As origens do investimento japonês na Ásia: um estudo do período da pré-Segunda Guerra Mundial. Revista de Economia Política, v. 30, n. 1 (117), 2010, p. 178-182.)

Os conectores permitem também ao resenhista fazer objeções ao livro ou introduzir exemplos para esclarecer melhor uma ideia. Neste trecho, a objeção ao livro é introduzida pelo ainda que, e o exemplo é introduzido pelo como.

(14) Ainda que a obra apresente problemas, como a repetição de ideias em demasia e um certo desequilíbrio na construção dos debates em cada capítulo, ela constitui obra de interesse. 
(TEODÓSIO, A. S. S. Ralé à brasileira. E \& G Economia e Gestão, v. 12, n. 29, 2012, p. 169-171.)

\section{Substantivos}

Os substantivos formam um conjunto de palavras que, segundo a definição da gramática, dá nomes aos seres e às coisas. Assim, o substantivo livro seria a palavra que nomeia o objeto livro. Haveria, então, uma relação de equivalência entre o objeto livro e a palavra livro. Mas será que a relação entre os substantivos e os seres é assim tão simples? Será que é possível pensar na palavra como uma mera etiqueta ou um rótulo que "colamos", atribuímos às coisas para identificá-las? A questão é complexa, e não temos a pretensão de resolvê-la. Mas é importante duvidarmos da definição que a gramática propõe para os substantivos, se quisermos entender melhor o funcionamento deles nas resenhas.

Suponhamos que dois jornalistas diferentes tenham noticiado uma manifestação de funcionários de uma empresa por melhores salários. Na notícia de um dos jornalistas, os funcionários foram nomeados por meio do substantivo manifestantes. Na outra, o substantivo usado para nomeálos foi baderneiros. Essa diferença no modo de se referir aos mesmos funcionários mostra uma clara divergência na maneira como cada jornalista interpreta o mundo e, portanto, refere-se aos seres. Essa diferença mostra, então, que os substantivos não parecem ser meras etiquetas que identificam as coisas. Nos textos que produzimos, os seres e os objetos são antes reconstruídos por nós, no momento em que nos referimos a eles, que simplesmente nomeados ( $\mathrm{KOCH}, 2006, \mathrm{MARCUSCHI}$, 
2008). Nas notícias, cada jornalista reconstruiu os funcionários de uma determinada maneira. Um, reconstruiu-os como manifestantes, como cidadãos reivindicando seus direitos. Outro, reconstruiu-os como baderneiros, como perturbadores da ordem estabelecida. Vejamos concretamente como isso ocorre neste trecho de uma reportagem.

(15) Nos últimos anos, as praias cariocas tornaramse lugares quase intransitáveis. Não apenas porque há mais gente. $\mathrm{O}$ maior tumulto é provocado pela turba de barraqueiros, camelôs e flanelinhas que tomou conta do pedaço. A ideia de que a orla do Rio era um espaço de convivência extremamente democrático serviu apenas como pretexto para a falta de organização. A baderna se espalhou.

(Revista Veja, jan. 2010. ed. 2146. p. 56)

Nesse trecho, o jornalista refere-se a um grupo de pessoas como turba de barraqueiros, camelôs e flanelinhas. Não é possível dizer que essa expressão, formada por vários substantivos, apenas nomeia o grupo. A turba de barraqueiros, camelôs e flanelinhas deve ser vista antes como uma reconstrução do próprio jornalista, reconstrução feita com base em valores, crenças, preconceitos. Outro jornalista poderia se referir a esse mesmo grupo de pessoas por meio da expressão conjunto de trabalhadores informais, o que nos levaria a ver esse grupo sob um ângulo bastante diferente. O que esse exemplo mostra, então, é que os substantivos não simplesmente dão nomes aos seres. Eles ajudam o produtor de um texto a recriar os seres da maneira que considera a mais interessante aos seus propósitos comunicativos. 
Do ponto de vista argumentativo, a compreensão de que os substantivos (re)criam, e não apenas nomeiam, os seres e objetos é fundamental. No trecho acima, é evidente a opinião contrária do jornalista com relação ao grupo de indivíduos mencionado. Ele não diz explicitamente que essas pessoas, para ele, deveriam ser banidas das praias ou que o seu comportamento deveria ser severamente punido. Mas deixa a opinião facilmente captável pela própria escolha dos substantivos usados para fazer referência a tal grupo.

Nessa mesma perspectiva, o papel dos substantivos para a construção da argumentação nas resenhas é de primeira importância, uma vez que eles vão permitir ao resenhista caracterizar a obra resenhada segundo seu ponto de vista. Assim, se é favorável, os substantivos usados vão refletir isso. O mesmo ocorre caso o ponto de vista seja desfavorável. Neste trecho de uma resenha, a opinião desfavorável é manifestada de modo veemente por meio de várias palavras, inclusive pelos substantivos marcados em itálico.

(16) Esse livro de Nivaldo Faria é mais um destes manuais que inundam a bibliografia da administração. Tudo não passa da mesma lengalenga. A própria Atlas lançou, recentemente, um livro de Fleury e Vargas sobre Organização do trabalho, cujo conteúdo é o mesmo do livro de Nivaldo Faria. Não há mais espaço para estas repetições enfadonhas, que não acrescentam nada de substantivo à gestão do processo de trabalho.

(FARIA, J. H. Organização do trabalho. Revista de Administração. v. 20, n. 1, 1985, p. 90. Disponível em: www.rausp.usp.br/download.asp?file=v20n01p087. pdf. Acesso em: 23/02/2014.) 
Referir-se a um trabalho acadêmico como "um destes manuais" é desqualificá-lo, é inseri-lo numa categoria de obras menos importantes. O mesmo ocorre quando o conteúdo do livro é caracterizado como lengalenga e como repetições (enfadonhas).

As observações e as análises apresentadas neste item mostram que a escolha das palavras não deve ser feita de forma descuidada, porque elas são extremamente relevantes para a construção de nossos textos, funcionando como poderosos recursos argumentativos. Na produção de uma resenha, não basta pensar em bons argumentos para defender uma opinião sobre a obra resenhada. É preciso verificar se os adjetivos, os advérbios, os conectores, os substantivos e outras palavras selecionadas para verbalizar esses argumentos estão mesmo a serviço da argumentação que queremos construir, ajudandonos a convencer o leitor.

\section{CONSIDERAÇÕES FINAIS}

Neste artigo, procuramos oferecer um conjunto de informações importantes sobre a construção da resenha acadêmica. Observamos que ela é um gênero de textos bastante argumentativo, embora não seja totalmente formada por segmentos argumentativos. Essa dimensão fortemente argumentativa da resenha se explica pela sua finalidade, que é a de convencer alguém a adquirir ou não uma obra recentemente publicada. Verificamos também que a resenha possui uma macroestrutura característica, que não deve ser vista como uma forma textual ou "camisa de força", mas 
que representa as ações que um resenhista costuma realizar na hora de escrever. Por fim, foi possível constatar o papel de primeira importância que a escolha das palavras tem na produção das resenhas e como uma palavra bem empregada tem o poder de direcionar a leitura, levando o leitor a crer no ponto de vista do autor.

Esperamos que o trabalho aqui apresentado possa auxiliar não só os estudiosos que pesquisam as características do gênero resenha, mas também os professores universitários que têm a tarefa de possibilitar aos estudantes o desenvolvimento de habilidades necessárias à produção e à compreensão desse gênero.

\section{REFERÊNCIAS}

ANTUNES, Irandé. Lutar com palavras: coesão e coerência. São Paulo: Parábola Editorial, 2005.

BAKHTIN, Mikhail/VOLOCHÍNOV, V. N. Marxismo $e$ filosofia da linguagem. São Paulo: Hucitec, 2012[1929].

CABRAL, Ana Lúcia Tinoco. A força das palavras: dizer e argumentar. São Paulo: Contexto, 2010.

CARVALHO, Gisele de. Gênero como ação social em Miller e Bazerman: o conceito, uma sugestão metodológica e um exemplo de aplicação. In: MEURER, J. L.; BONINI, A.; MOTTA-ROTH, D. (orgs.) Gêneros: teorias, métodos, debates. São Paulo: Parábola Editorial, 2005, p. 130-149.

CUNHA, Gustavo Ximenes. A função de conectores argumentativos no texto da proposta curricular de Minas Gerais. Alfa, v. 54, p. 203-222, 2010. 
CUNHA, Gustavo Ximenes. A articulação discursiva do gênero artigo de opinião à luz de um modelo modular de análise do discurso. Filologia e Linguística Portuguesa, v. 14, p. 73-97, 2012.

$\mathrm{KOCH}$, Ingedore Villaça. Desvendando os segredos do texto. São Paulo: Cortez, 2006.

MARCUSCHI, Luiz Antônio. Produção textual, análise de gêneros e compreensão. São Paulo: Parábola Editorial, 2008.

MATENCIO, Maria de Lourdes Meirelles. Referenciação $e$ retextualização de textos acadêmicos: um estudo do resumo e da resenha. In: Anais do III Congresso Internacional da ABRALIN, 2003, p. 1-10.

MOTTA-ROTH, Désirée. A construção social do gênero resenha acadêmica. Trabalhos de Linguística Aplicada, v. 38, p. 29-45, 2001.

MOTTA-ROTH; Désirée; HENDGES, Graciela Rabuske. Produção textual na universidade. São Paulo: Parábola Editorial, 2010.

ROULET, Eddy. The description of text relation markers in the Geneva model of discourse organization. In: FISCHER, K. (ed.). Approaches to Discourse Particles. Amsterdam: Elsevier, 2006, p. 115-131.

\section{ABSTRACT}

In this paper, we conducted a study of the academic review. Three reasons justify the study of this genre. Firstly, the review is a genre in which academic argumentation is central. Secondly, it is an important instrument of circulation and 
consolidation of knowledge in the different areas of knowledge. Thirdly, this genre of texts is one of the most requested by teachers in different stages of a college degree. Based on the descendant perspective proposed by Bakhtin/Volochínov, the present study does not limit the understanding of the genre to its formal aspects of composition. Without disregard those aspects, the study begins with the contextual dimension of the review. Then, it focuses the macrotexture of the genre. Finally, it studies their linguistic dimension.

Keywords: Academic review. Argumentation. Genres.

\section{Gustavo Ximenes Cunha}

Mestre e doutor em Linguística pela Universidade Federal de Minas Gerais (UFMG), onde desenvolveu pesquisa de pósdoutorado de 2014 a 2015. É professor adjunto do Instituto de Ciências Sociais Aplicadas e do programa de pós-graduação em Gestão Pública e Sociedade da Universidade Federal de Alfenas (Unifal-MG). É pesquisador do grupo de estudos sobre a Articulação do Discurso e do grupo de estudos da Oralidade e da Escrita, ambos da UFMG. Seus trabalhos mais recentes investigam, numa perspectiva cognitivo-interacionista, o impacto do contexto sobre diferentes planos da organização do discurso.

ximenescunha@yahoo.com.br 